\title{
DRONE PROPELLER BLADE MATERIAL OPTIMIZATION USING MODERN COMPUTATIONAL METHOD
}

\author{
Jan Krmela ${ }^{1}$, Alzbeta Bakosova ${ }^{1}$, Vladimira Krmelova ${ }^{1}$, Sylvain Sadjiep ${ }^{2}$ \\ ${ }^{1}$ Alexander Dubcek University of Trencin, Slovakia; ${ }^{2}$ University of Pardubice, Czech Republic \\ jan2.krmela@post.cz, alzbeta.bakosova@student.tnuni.sk, jan.krmela@upce.cz, \\ bauricesylvain.sadjieptchuigwa@student.upce.cz
}

\begin{abstract}
The paper deals with the optimization of the material of the propeller blade Drone DJI Mavic Pro using a modern computational method in order to find a suitable material for 3D printing. For computational simulation, ANSYS Discovery Live 2019 was used as a modern computational method. SolidWorks 2020 was used to create a 3D model of the propeller blade. ABS, PLA, PETG were selected as suitable materials for the drone propeller blade, which will be produced by 3D printing. One of them was thought that would best meet all requirements. Computational models were made for this purpose. Deformation-stress states were calculated and calculations as "a wind tunnel" were done. It was a simulation of the take-off of a drone as a solution of rotation of one blade in a wind tunnel with defined different temperatures and rotational speeds. The results of these simulations are evaluated. The highest stress values in the blade area were for the ABS material and the lowest for the PLA material. In the area of the propeller legs, which simulate attachment to the drone, the ABS material showed the highest stress values and the PETG material showed the lowest stress values. The largest deformation in the part of the leaf sheets was recorded by the ABS material and the lowest by PLA. The flight and flight conditions simulations were simulated at different temperatures of -2 and $+25^{\circ} \mathrm{C}$ and flight times of 1 and $10 \mathrm{~s}$ for each material. Based on the computational results, the PETG material was selected for 3D printing of the drone propeller blade.
\end{abstract}

Keywords: drone, ANSYS Discovery, 3D print, PETG.

\section{Introduction}

Drones or remotely piloted aircraft are quite costly, and their prices can climb from hundreds to thousands of euros, despite the diversity of the market and their easy availability. Their fragile construction is often tested and exposed to adverse weather conditions and terrain variability. Drone propeller blades are most often broken parts during imperfect landing or in collision with outdoor objects. The use of modern computational technology, the design of a suitable shape and the optimization of the material will contribute to the construction of a corresponding blade using a 3D printer based on the FDM principle [1;2]. In this article modern simulation software Ansys Discovery Live was used, which is relatively new to the market. By using modern computational technology in cooperation with 3D printing, the designer gets quick response and thus the opportunity to work faster and cheaper towards the final product. This article deals with the propeller for the specific drone DJI mavic PRO [3]. The aim of the work was to create geometry and optimize the material of the drone propeller blade using a modern calculation method in the program Ansys Discovery Live 2019 for 3D printing of the designed variant. There are articles $[4 ; 5]$ that deal with computational fluid dynamics (CFD) analysis of a drone propeller in Ansys FLUENT/CFX. The new program Ansys Discovery Live used in this article uses GPU only for fast calculations. The authors did not find a similar calculation study of a drone propeller blade which used Ansys Discovery Live.

\section{Materials and methods}

The SolidWorks 2020 environment was used to create the model of the drone propeller. The overall dimensions, such as length, width, thickness, rounding, and layout of the propeller legs, were inspired by the original part made for the drone by the manufacturer. Thus, compatibility was achieved, so it can be used for a given drone when finished.

The formation of the propeller blade model was created from 6 smaller drawings combined into one profile (Fig. 1), in which the parameters of angles and radii were determined and adjusted in order to get the optimal shape and properties of the blade. Using the function add by extrusion and subsequent mirroring, the primary shape of the propeller was obtained. Details and final adjustments were made with the functions round, add and remove by extrusion, circular pattern and nineteen different sketches (Fig. 2). The tested materials ABS, PLA and PETG [6] were defined by material parameters, for example, material parameters of PETG as inputs to simulations are shown in Fig. 3. 
The value of the tensile strength, depending on the manufacturer of the materials, the process used and the 3D printer itself, are given for ABS in the range from 60 to $150 \mathrm{MPa}$. For PLA, the tensile strength ranges from 50 to $135 \mathrm{MPa}$ and the range of PETG is from 45 to $140 \mathrm{MPa}$ [7].

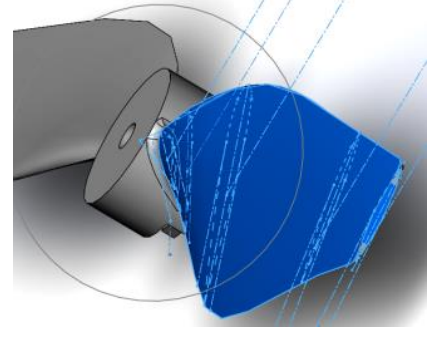

Fig. 1. Profile of the propeller blade

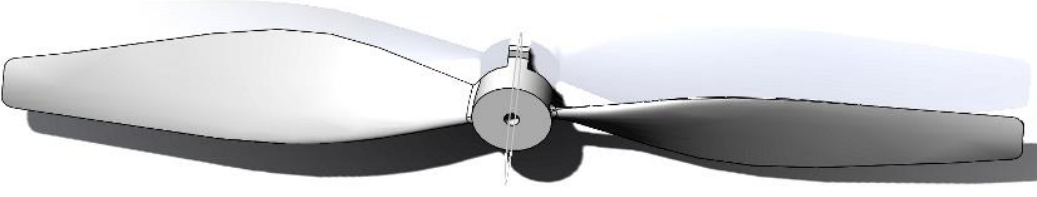

Fig. 2. Final shape of the propeller

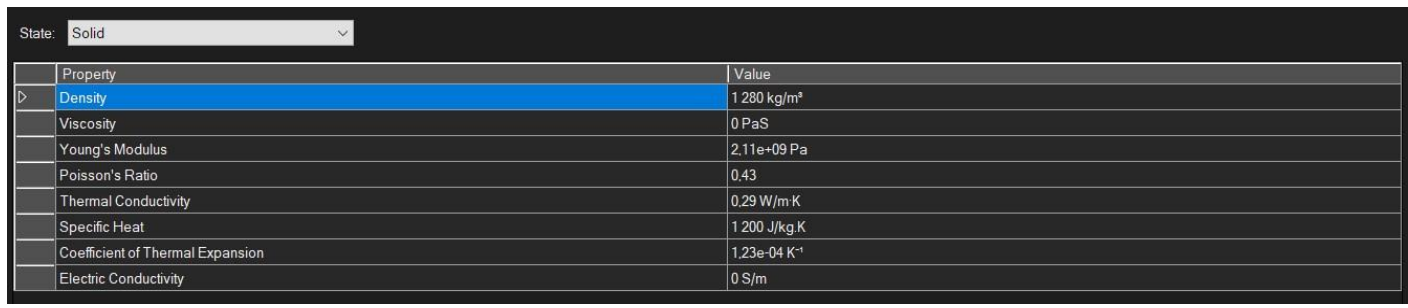

Fig. 3. Material parameters of PETG defined in ANSYS Discovery Live

Conditions for the simulations were defined including gravity $9.81 \mathrm{~m} \cdot \mathrm{s}^{-1}$, the direction of the rotation propeller speed $5500 \mathrm{rpm}(88.3 \mathrm{rps})$ that was determined from the drone manufacturer data. The pressure applied to the surface of the blade from the bottom is $5882.63 \mathrm{~Pa}$ for each blade. As the bottom surface of the blade is about $1667 \mathrm{~mm}^{2}$ [8], in conversion this corresponds to force of $9.8 \mathrm{~N}$ for one blade and $19.6 \mathrm{~N}$ (this equals to $2 \mathrm{~kg}$ ) per whole propeller. Listed applied pressure was calculated from the real weight of the drone, its acceleration, the maximum speed of ascent and descent. Final weight was $8 \mathrm{~kg}$, i.e. the force of $78.5 \mathrm{~N}$. The force acting on the blades was applied (Fig. 4) and constraint fixed support was applied on all three legs of the propeller, which in real model represents the securing and connection between the drone and the propeller.

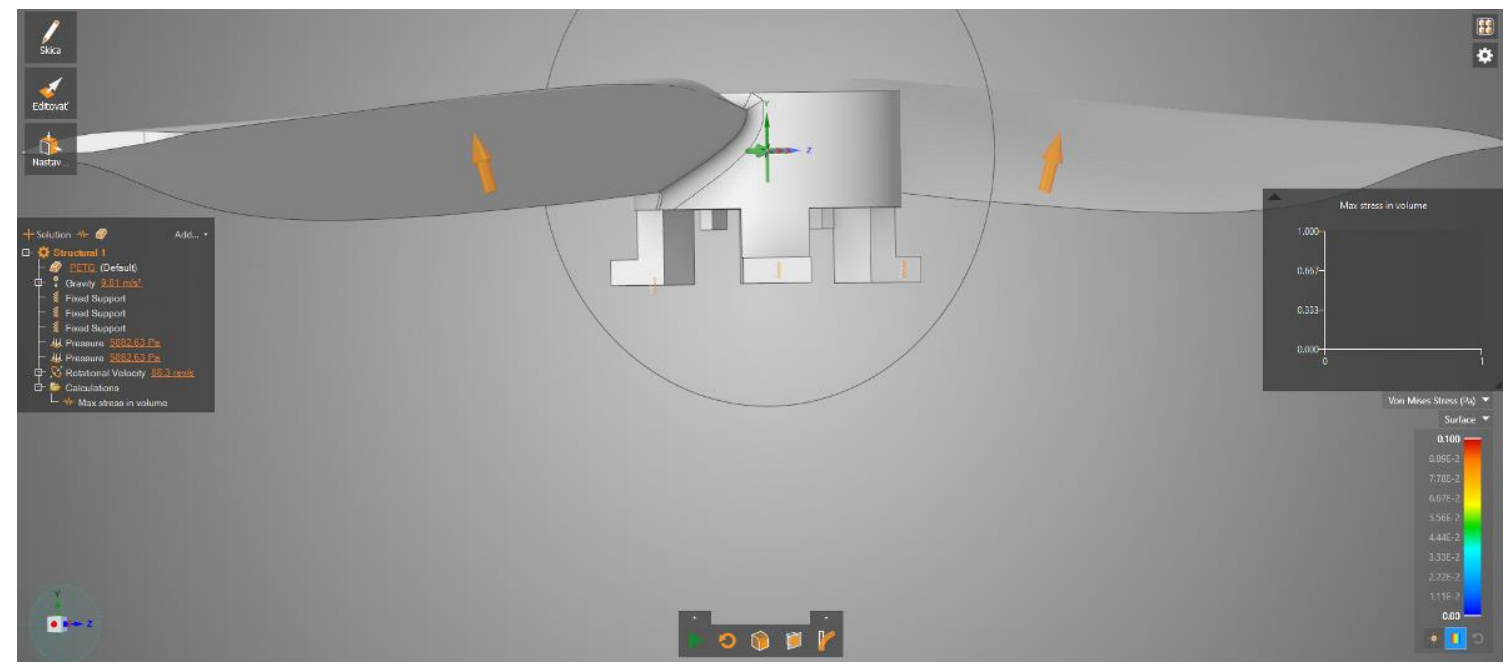

Fig. 4. Forces applied on blades of the propeller

The first computational analyses were performed to obtain the maximum reduced stress on the propeller blades and the propeller legs. A surface area of one leg is $6.44 \mathrm{~mm}^{2}$ according to the calculation from the program SolidWorks, so the calculated pressure is approx. 1.015 MPa based on the force of $19.6 \mathrm{~N}$. The pressure was applied to each leg in direction from top to bottom, which simulates the real 
fastening of the propeller in the drone. Boundary conditions of the propeller legs are shown in Fig. 5. Deformation of the propeller blade can be seen in Fig. 6.

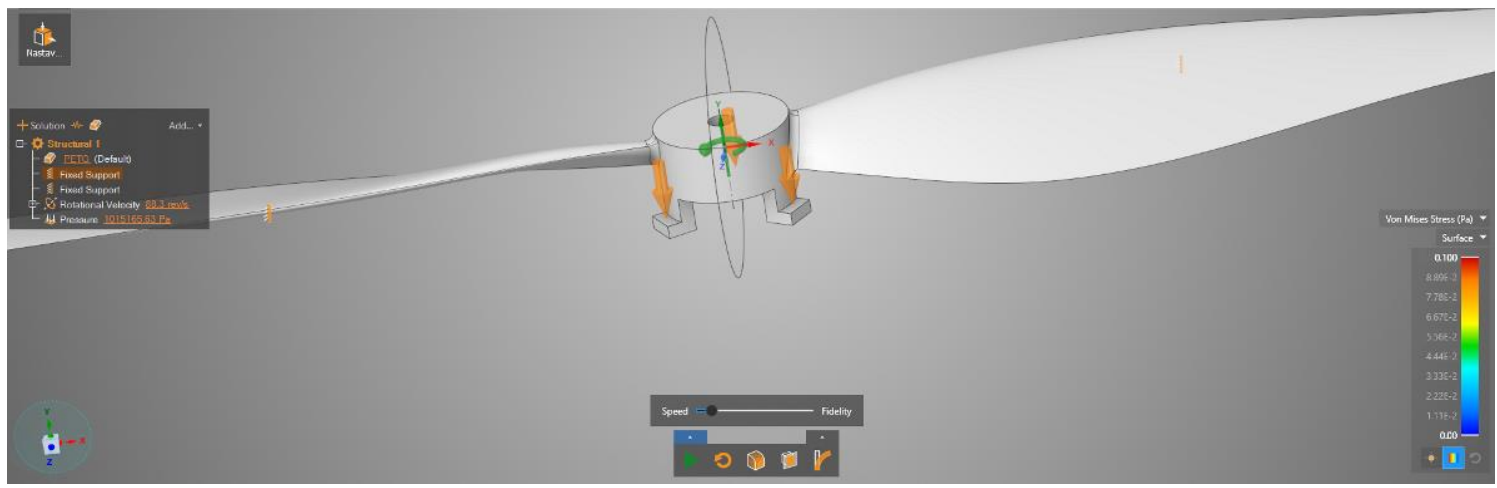

Fig. 5. Boundary conditions of propeller legs

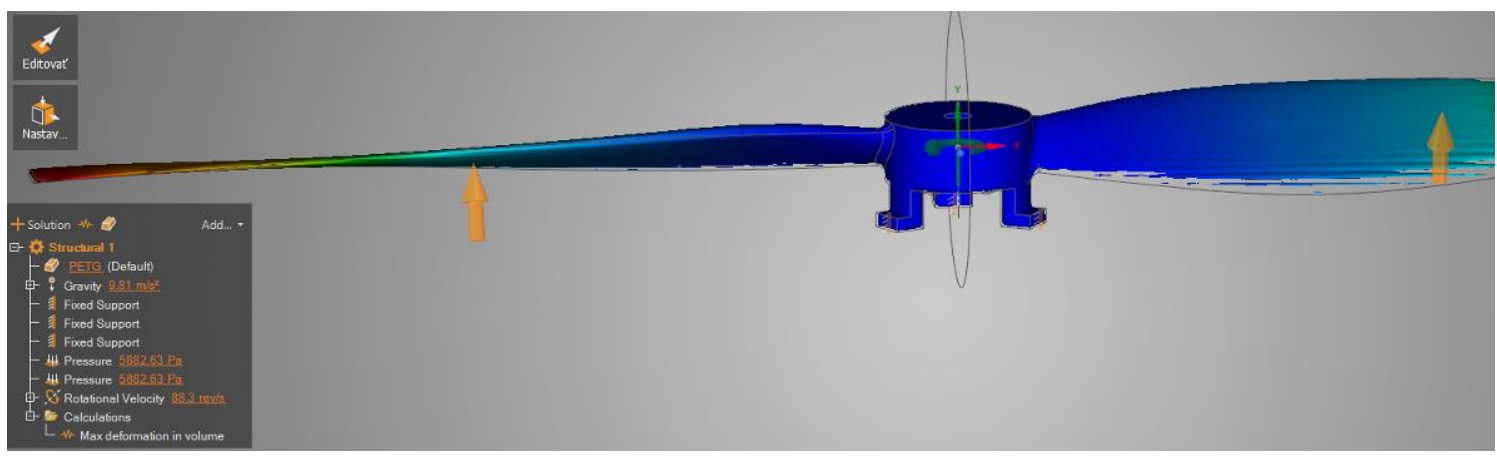

Fig. 6. Deformation of the propeller blade

For the second simulation addressing the drone take-off a wind tunnel was created, in which the wind speed was determined according to the Beafurt wind scale and a gentle breeze of $19 \mathrm{~km} \cdot \mathrm{h}^{-1}$ was selected in order to achieve normal weather conditions during the drone flight [8]. This simulation was performed for different air temperatures, namely -2 and $+25^{\circ} \mathrm{C}$, and for different flight times of 1 and 10 s. An example of input parameters for air flow simulation is shown in Fig. 7.

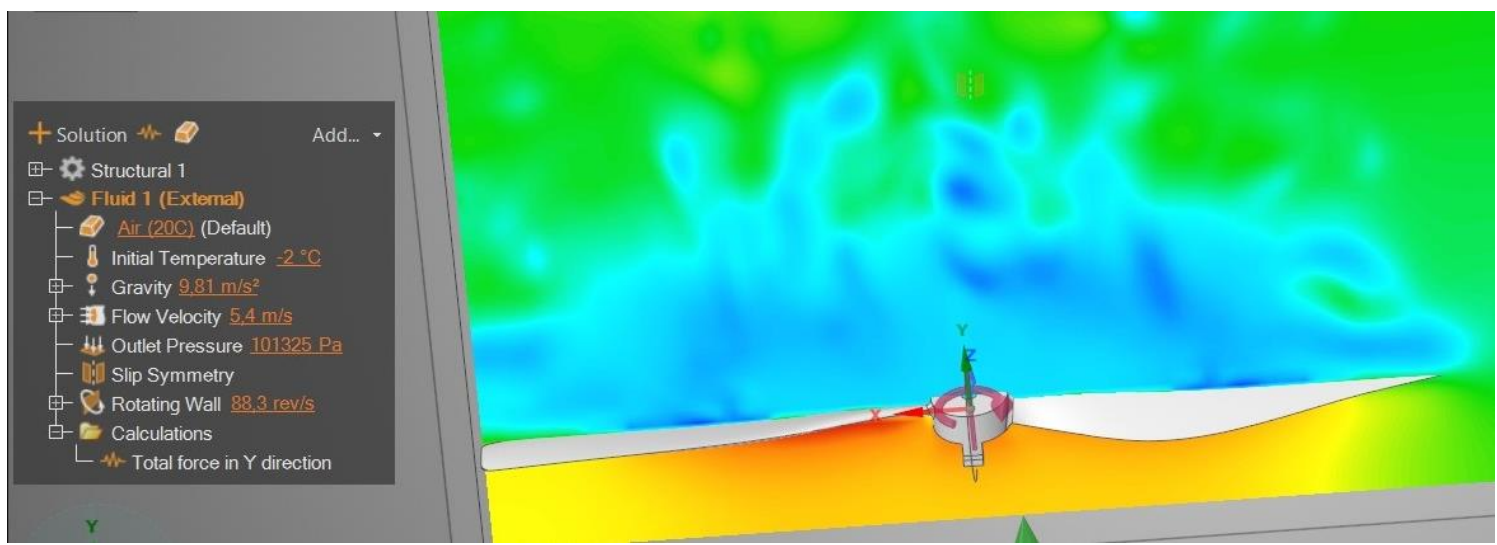

Fig. 7. Take-off simulation in the environment of the program ANSYS Discovery live

\section{Results and discussion}

The highest value of Von Mises stress in the propeller blades was computed for the ABS blade, which was 145.5 MPa. The second highest value of 140.3 MPa belonged to the PETG blade (Fig. 8). The lowest value was 55.4 MPa for the blade made of PLA, which is $62 \%$ lower than for the blade made of ABS. 


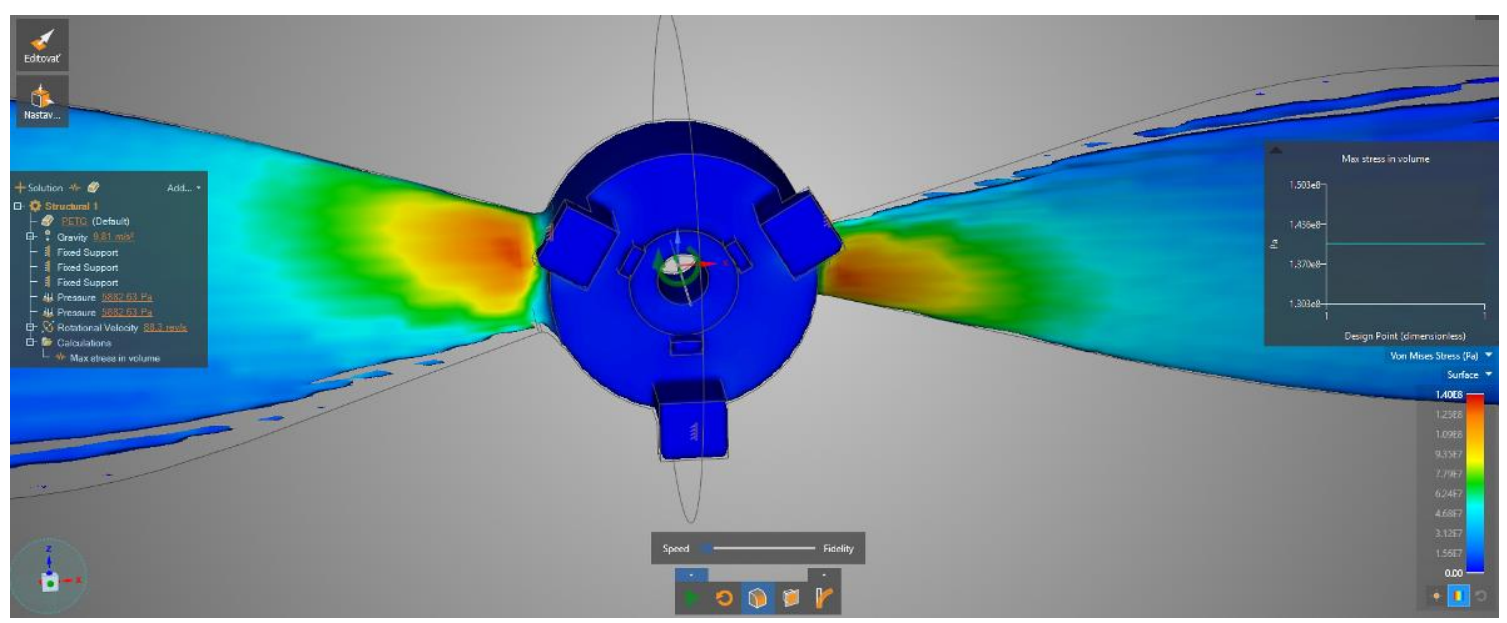

Fig. 8. Maximum stress in propeller blades for PETG

The lowest stress values in the propeller legs were 5.95 MPa for the PLA propeller material. Stress for the PETG propeller was 5.88 MPa (Fig. 9), which is the lowest stress value from all materials, and the highest stress of $5.96 \mathrm{MPa}$ was in the ABS propeller.

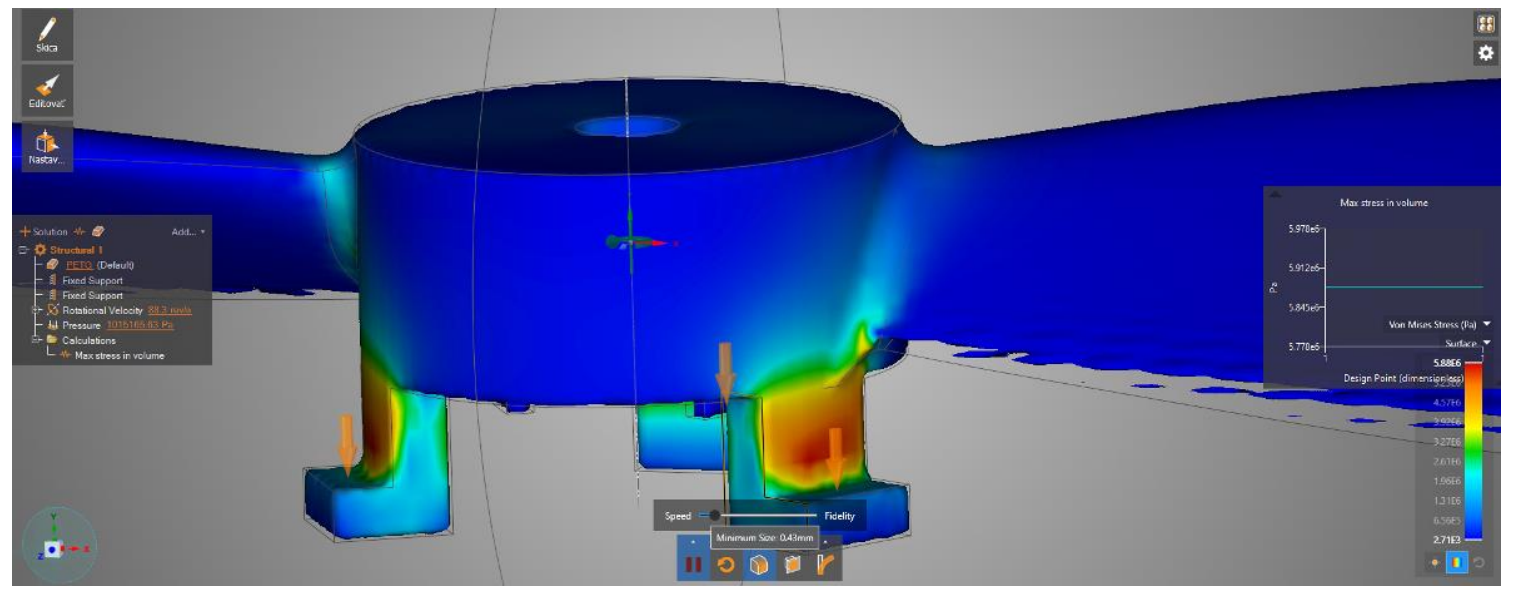

Fig. 9. Maximum stress in propeller legs for PETG

When analysing the maximum deformation of the propeller blades, it can be noted that for all materials the highest deformation values can be observed in the area of the blade edge. For material ABS, the highest deformation values were $88.1 \mathrm{~mm}$. In comparison, PLA blade deformation values were the lowest $42.6 \mathrm{~mm}$, which was $52 \%$ less compared to ABS. PETG showed deformation values of 45.7 $\mathrm{mm}$, which was $48 \%$ less compared to ABS [8].

From analysis of the maximum deformation of the propeller legs it can be concluded that ABS showed the highest values of deformation $0.087 \mathrm{~mm}$ and PLA had the lowest values $0.041 \mathrm{~mm}$, which was 53\% less compared to ABS and for PETG the maximum deformation was $0.048 \mathrm{~mm}(45 \%$ less compared to ABS).

In the simulation of flight and flight conditions at different temperatures and flight times different values of the forces acting on the propeller in the direction of the $y$-axis (vertical direction) were achieved. When comparing the flight time of 1 and $10 \mathrm{~s}$, forces for each material were higher at the flight time of $10 \mathrm{~s}$ and difference at temperature $-2{ }^{\circ} \mathrm{C}$ was $21 \%$ for ABS, $2 \%$ for PLA and $12 \%$ for PETG (Fig. 10). At $+25^{\circ} \mathrm{C}$ comparing flight times of 1 and $10 \mathrm{~s}$, the difference in values was $22 \%$ for ABS, $0 \%$ for PLA and 5\% for PETG (Fig. 11).

In the simulation of the flight time $10 \mathrm{~s}$ there was higher force acting on the blade compered to the flight time $1 \mathrm{~s}$. The PETG material showed smaller force acting on the blade at temperature $-2{ }^{\circ} \mathrm{C}$ (Fig. 12) with a $4 \%$ difference compared to the results at $+25^{\circ} \mathrm{C}$ (Fig. 13). 


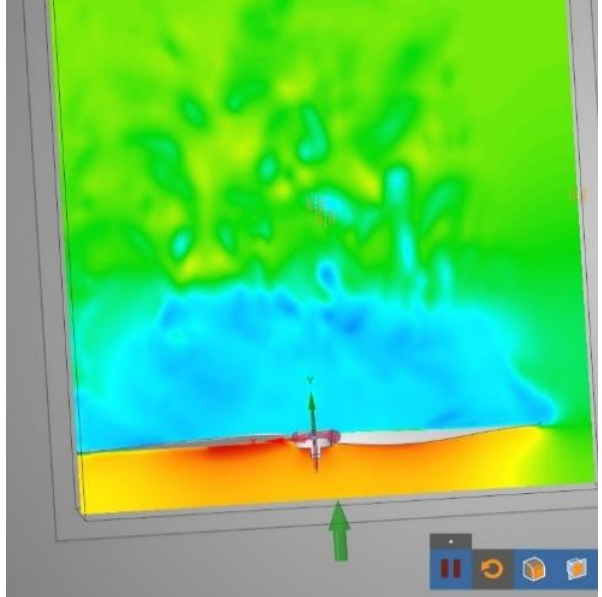

Fig. 10. PETG for $1 \mathrm{~s}$ and $-2^{\circ} \mathrm{C}$

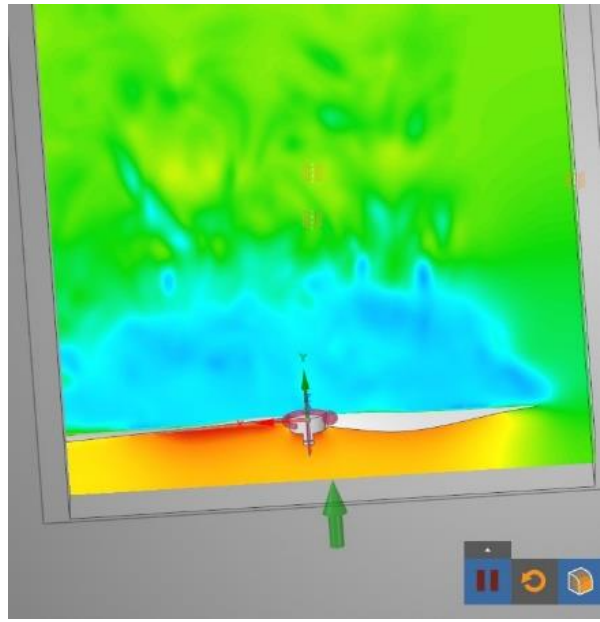

Fig. 12. PETG for $10 \mathrm{~s}$ and $-2^{\circ} \mathrm{C}$

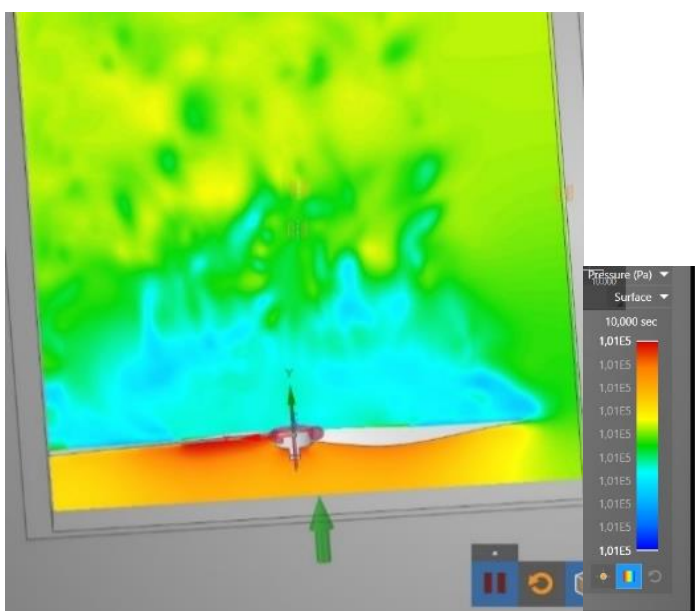

Fig. 11. PETG for $1 \mathrm{~s}$ and $+25^{\circ} \mathrm{C}$

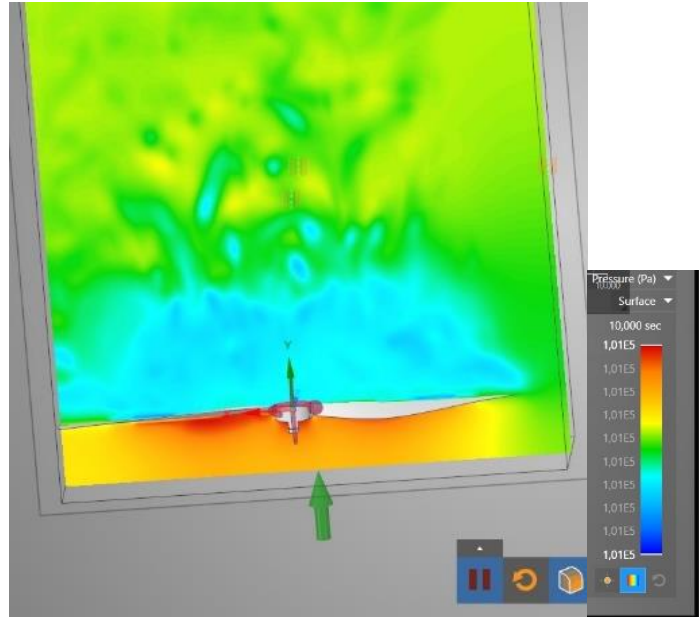

Fig. 13. PETG for $10 \mathrm{~s}$ and $+25^{\circ} \mathrm{C}$

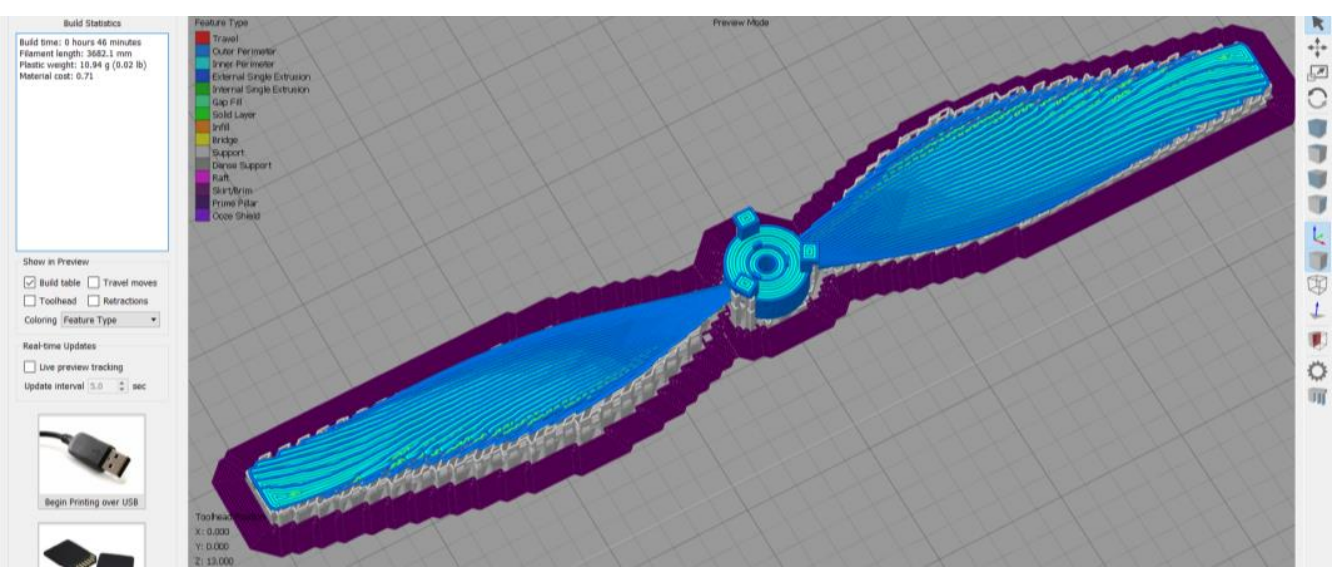

Fig. 14. Simplify $\mathbf{- 3 D}$ model

Based on the simulation results the material PETG was selected for 3D printing. 3D printing and preparation of model and printing parameters was performed by the main author of this article. Printing was realised by 3D printer German RepRap X400 V3 with the application Simplify (Fig. 14), where auxiliary supports for 3D printing of geometrically demanding components were created.

A prototype of the propeller was made by 3D printing. A $0.8 \mathrm{~mm}$ nozzle was used for fast printing (Fig. 15). The printout cannot be used for drone take-off, the purpose was to verify the possibility of producing complex geometry by $3 \mathrm{D}$ printing. 


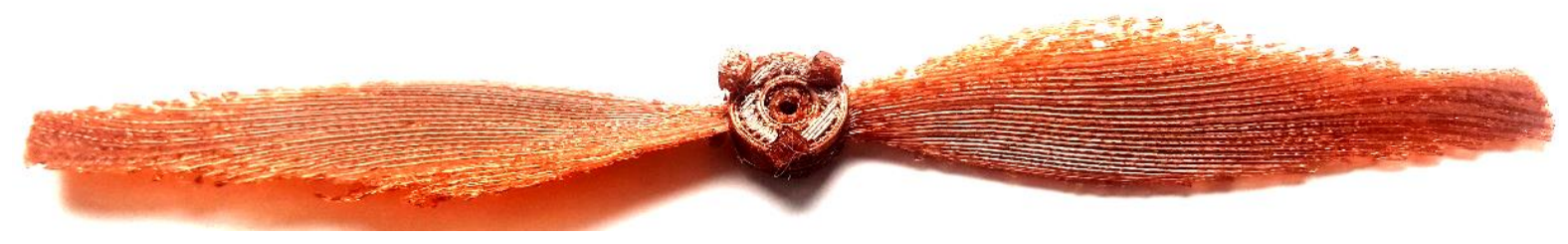

Fig. 15. Prototype of 3D printed propeller

\section{Conclusions}

1. Based on the calculations, it can be concluded that the material ABS showed the highest values of the maximum stress for both critically loaded areas of the propeller and therefore it is unsatisfactory.

2. Based on the performed simulations and the results from them, it can be stated that PETG is a suitable material for the drone propeller.

3. Higher forces occurred at simulations of longer flight time $10 \mathrm{~s}$ and positive temperature $+25^{\circ} \mathrm{C}$ with small percentage differences up to $22 \%$ between the materials.

4. A propeller made of the material PETG was produced by 3D printing. This prototype was used to verify suitability of the propeller geometry and selected material for 3D printing. For further research, a nozzle with a diameter of $0.25 \mathrm{~mm}$ will be applied and it is planned to verify whether a 3D-printed propeller made by a given printer can be used for a real take-off of the drone.

\section{Acknowledgements}

This research work had been supported by the Cultural and Educational Grant Agency of the Slovak Republic (KEGA), projects No. KEGA 002TnUAD-4/2019 and KEGA 002TnUAD-4/2020 and the project "Advancement and support of R\&D for "Centre for diagnostics and quality testing of materials" in the domains of the RIS3 SK specialization", code NFP313011W442.

\section{References}

[1] Fused Deposition Modeling (FDM). [online] [15.03.2021]. Available at: https://www.additively.com/de/lernen/fused-deposition-modeling

[2] DJI mavic PRO. [online] [15.03.2021]. Available at: https://www.dji.com/sk/mavic

[3] Kumar L.J., Pandey P.M. and Wimpenny D.I., eds. 3D Printing and Additive Manufacturing Technologies. Singapore: Springer Singapore, 2019. ISBN 978-981-13-0304-3. DOI: 10.1007/978981-13-0305-0.

[4] Kutty H.A. and Rajendran P. 3D CFD Simulation and Experimental Validation of Small APC Slow Flyer Propeller Blade. Aerospace. 2017, 4(1):10. DOI: 10.3390/aerospace4010010.

[5] Christodoulou K., Vozinidis M., Karanatsios A., Karipidis E., Katsanevakis F. and Vlahostergios Z. Aerodynamic Analysis of a Quadcopter Drone Propeller with the Use of Computational Fluid Dynamics. Chemical Engineering Transactions. 2019, 76, 181-186.

[6] PLA vs ABS, PETG, TPU for 3D Printing - Comparison \& Guide. [online] [15.03.2021]. Available at: https://the3dprinterbee.com/pla-vs-abs-vs-petg-vs-tpu-3d-printing-filament-guide

[7] Krajčoviech J. (leader Krmela J.) Use of 3D printing for the production of spare parts for automotive. 2020. Diploma thesis, Faculty of Industrial Technologies, Alexander Dubček University of Trenčín, Púchov, Slovak Republic. (In Slovak)

[8] Kováčik J. (leader Krmela J.) Optimization of the shape and material of the propeller blade for drone using a modern calculation method for 3D printing of the proposed variant. 2020. Diploma thesis, Faculty of Industrial Technologies, Alexander Dubček University of Trenčín, Púchov, Slovak Republic. (In Slovak) 